\title{
EDITORIAL
}

\section{Hacia una nueva ley de huelga}

Nuestra Constitución, en su articulo 28.2 reconoce el derecho de huelga entre los derechos fundamentales de los ciudadanos. Escribe: "Se reconoce el derecho a la huelga de los trabajadores para la defensa de sus intereses". En lo cual concuerda con la doctrina del Concilio Vaticano II, cuando dice en el número 68 de la Constitución Gaudium et Spes: "En caso de conflictos económico-sociales hay que esforzarse por encontrarles soluciones pacificas. Aunque se ha de recurrir siempre a un sincero diálogo entre las partes, sin embargo, en la situación presente, la huelga puede seguir siendo medio necesario, aunque extremo, para la defensa de los derechos y el logro de las aspiraciones justas de los trabajadores. Búsquense, con todo, cuanto antes, caminos para negociar y para reanudar el diálogo conciliatorio."

Esta enseñanza de/ Vaticano // es complementada por la enciclica Laborem Exercens, de Juan Pablo ll, con estas palabras: "Admitiendo que es un medio legítimo, se debe subrayar al mismo tiempo que la huelga sigue siendo, en cierto sentido, un medio extremo. No se puede abusar de él; no se puede abusar de él especialmente en función de los "juegos políticos". Por lo demás, no se puede jamás olvidar que cuando se trata de servicios esenciales para la convivencia civil, éstos han de asegurarse en todo caso mediante medidas legales apropiadas si es necesario. El abuso de la huelga puede conducir a la paralización de toda la actividad socioeconómica, y esto es contrario a las exigencias del bien común de la sociedad, que corresponde también a la naturaleza bien entendida del trabajo mismo" (n.. 20).

Algo de esto es lo que tiene en cuenta nuestra Constitución en ese mismo artículo 28.2, cuando afirma: "La ley que regule el ejercicio de este derecho establecerá las garantías precisas para asegurar ei mantenimiento de los servicios esenciales de la comunidad."

A finales de abril pasado la prensa dio a conocer el texto integro del anteproyecto de ley de huelga elaborado por el Gobierno. Los sindicatos han reaccionado en contra de todo proyecto de ley de huelga; piensan que esta última no es necesaria; que es suficiente el autocontrol y la responsabilidad sindical. 


\section{Editorial}

Se comprende esta postura de los sindicatos; prefieren, naturalmente, plena libertad de acción, sin trabas legales especificas, para la defensa de los derechos y aspiraciones de los trabajadores. Pero ef Estado es responsable de los intereses legítimos no sólo de la clase obrera sino de toda la comunidad política y ha de velar, pues, por la armonización y compatibilidad de derechos e intereses de los diferentes grupos sociales. Por ello estimamos oportuno el cumplimiento del mandato constitucional sobre la elaboración, aprobación y promulgación de una nueva ley de huelga. Los derechos armónicos y generales de toda la sociedad deben tener prioridad incluso sobre los mismísimos de la clase obrera. Esta última, en efecto, forma también parte de aquella comunidad política, cuyos intereses generales se trata de defender.

Por otro lado, el citado anteproyecto de ley da un amplio lugar a la autorregulación sindical. Escribe en su artículo 14: "Las organizaciones sociales más representativas y las que gocen de representación en el ámbito correspondiente, podrán establecer, de manera conjunta, normas de autorregulación del ejercicio del derecho de huelga para el mantenimiento de los servicios esenciales de la comunidad en sectores o empresas relacionados con las actividades enumeradas en el art. 11.1 (las que cuidan servicios esenciales, como sanidad, etc.). Dichas normas se presentarán en el Ministerio de Trabajo o en el órgano de la correspondiente comunidad autónoma, quienes las aprobarán o rechazarán mediante resolución motivada... Igualmente, las organizaciones citadas podrán concluir con las organizaciones empresariales o las administrativas afectadas acuerdos especificos de regulación del ejercicio del derecho de huelga para el mantenimiento de los servicios esenciales de la comunidad..."

El texto del anteproyecto de ley nos parece bueno y equilibrado, en líneas generales. Garantiza bien el ejercicio del derecho fundamental a la huelga, a la vez que establece determinadas condiciones para la salvaguarda de los servicios esenciales y la responsabilidad sindical en la práctica de aquel ejercicio.

Sólo deseariamos que, en lo que queda del proceso de discusión. aprobación y promulgación de la ley, se cumpliera lo que pide el articulo 131.2 de la Constitución: "El Gobjerno elaborará los proyectos de planificación, de acuerdo con... el asesoramiento y colaboración de los sindicatos y de otras organizaciones profesionales, empresariales y económicas." Pensamos que de tal diálogo y asesoramiento extraparlamentario puede resultar, efectivamente, aquel equilibrio mejorado. 